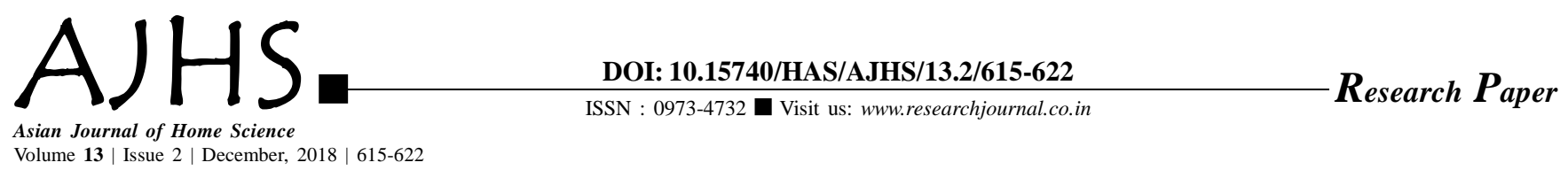

\title{
Status of writing readiness of urban school children with poor handwriting
}

\author{
Hijam Laxmi Chanu, Deepika Vig and Sarita Saini
}

See end of the paper for authors' affiliations

Hijam Laxmi Chanu Department of Human Development and Family Studies, Punjab Agricultural University, Ludhiana (Punjab) India Email : laxhijam66@gmail.com

Received: 06.07.2018; Revised: 08.11.2018; Accepted: 22.11 .2018

ABSTRACT : The present study was designed to identify urban school children with poor handwriting in English and explore their level of writing readiness. A sample of 60 children from grade 3 in the age group of 7-9 years was drawn from two public schools of Ludhiana city with average or above average intellectual abilities. Raven's Coloured Progressive Matrices (Raven, 1965) was used to identify the intellectual abilities of children. Occupational Therapy Screening Test (Lilley, 2006) Set A was used to assess the handwriting skills of the children. Writing Readiness Assessment Tool was used to assess different pre-writing skills. Finding of the study revealed that more than half of the children with poor handwriting skills were found to have poor writing readiness skills followed by average and good level. It was further found that in all the dimensions of writing readiness, major proportion of children had poor level of performance. Out of all the dimensions of writing readiness, 'Moving from freedom to confinement' was found to be poorest skill in children with poor handwriting.

KEY WORDS: Poor handwriting, Writing readiness, Moving from freedom to confinement

- HOW TO CITE THIS PAPER : Chanu, Hijam Laxmi, Vig, Deepika and Saini, Sarita (2018). Status of writing readiness of urban school children with poor handwriting. Asian J. Home Sci., 13 (2) : 615-622, DOI: 10.15740/HAS/AJHS/13.2/615-622. Copyright@ 2018: Hind Agri-Horticultural Society. 